\title{
Independent external validation and comparison of prevalent diabetes risk prediction models in a mixed-ancestry population of South Africa
}

\author{
Katya Masconi ${ }^{1,2}$, Tandi E. Matsha ${ }^{3}$, Rajiv T. Erasmus ${ }^{1}$ and Andre P. Kengne ${ }^{2,4^{*}}$
}

\begin{abstract}
Background: Guidelines increasingly encourage the use of multivariable risk models to predict the presence of prevalent undiagnosed type 2 diabetes mellitus worldwide. However, no single model can perform well in all settings and available models must be tested before implementation in new populations. We assessed and compared the performance of five prevalent diabetes risk models in mixed-ancestry South Africans.

Methods: Data from the Cape Town Bellville-South cohort were used for this study. Models were identified via recent systematic reviews. Discrimination was assessed and compared using C-statistic and non-parametric methods. Calibration was assessed via calibration plots, before and after recalibration through intercept adjustment.

Results: Seven hundred thirty-seven participants (27\% male), mean age, 52.2 years, were included, among whom $130(17.6 \%)$ had prevalent undiagnosed diabetes. The highest c-statistic for the five prediction models was recorded with the Kuwaiti model [C-statistic 0.68: $95 \%$ confidence: 0.63-0.73] and the lowest with the Rotterdam model [0. 64 (0.59-0.69)]; with no significant statistical differences when the models were compared with each other (Cambridge, Omani and the simplified Finnish models). Calibration ranged from acceptable to good, however over- and underestimation was prevalent. The Rotterdam and the Finnish models showed significant improvement following intercept adjustment.
\end{abstract}

Conclusions: The wide range of performances of different models in our sample highlights the challenges of selecting an appropriate model for prevalent diabetes risk prediction in different settings.

\section{Background}

Diabetes mellitus, type 2 diabetes in particular, is a growing epidemic worldwide with developing countries currently paying the highest toll [1]. In 2013 there were approximately 382 million individuals with type 2 diabetes, and this number will surge to approximately 592 million by 2035 [1]. This rapid rise of diabetes will result in an even greater and more profound burden which developing countries are not equipped to handle. Type 2 diabetes in developing countries is further characterized by a low detection rate with a high proportion of people being undiagnosed. Strategies are therefore needed for

\footnotetext{
* Correspondence: apkengne@yahoo.com

${ }^{2}$ Non-Communicable Diseases Research Unit, South African Medical Research Council, Cape Town, South Africa

${ }^{4}$ Department of Medicine, Groote Schuur Hospital, University of Cape Town, Cape Town, South Africa

Full list of author information is available at the end of the article
}

early detection and risk stratification such that treatment measures can be implemented to prevent the onset or delay the progression of related complications.

The use of multivariable risk prediction models has been advocated as practical and potentially affordable approaches for improving the detection of undiagnosed diabetes. Accordingly, guidelines, including those of the International Diabetes Federation, increasingly promote the use of reliable, simple and practical risk scoring systems or questionnaires and derivatives for diabetes risk screening around the world [2,3]. During the last two decades, numerous diabetes prediction models have been developed. However, only a few models have been externally validated, and generally not in developing countries $[4,5]$. Consequently, many developing countries have to rely on prediction models developed in other populations and not necessarily validated in their context. However, issues relating to differences in case-mix across 
populations, inherent to the development of models, can severely affect the applicability of a model in different settings $[6,7]$.

This study aimed to validate and compare the performance of selected common models for predicting prevalent undiagnosed diabetes based upon noninvasively measured predictors, in mixed ancestry South Africans.

\section{Methods}

\section{Study population and design of study}

The Cape Town Bellville-South study data served as the basis for models validation [8]. Bellville-South is located within the Northern suburbs of Cape Town, South Africa and is a traditionally a mixed-ancestry township formed in the late 1950s. According to the 2001 population census, its population stands at approximately 26,758 with $80.48 \%(21,536)$ consisting of the mixed ancestry individuals [22]. The study was approved by the Ethics Committee of the Cape Peninsula University of Technology (CPUT/HW-REC 2008/002 and CPUT/HW-REC 2010) and Stellenbosch University (N09/05/146).

The Bellville South Study was a cross-sectional study conducted from mid-January 2008 to March 2009 (cohort 1), and from January 2011 to November 2011 (cohort 2). The target population for this study were subjects $\geq 35 \mathrm{y}$. Using a map of Bellville South obtained from the Bellville municipality, random sampling was approached as follows: first, the area was divided into six strata; second, within each strata the streets were classified as short ( $\leq 22$ houses), medium (23-40 houses) and long ( $\geq 40$ houses) streets based on the number of houses. Two of each respective streets were randomly selected from each strata. In those instances where the numbers of houses were too few, a short or a medium street was randomly selected and added to such a stratum. The result was a total of 16 short streets representing approximately 190 houses, 15 medium (approximately 410 houses) and 12 long streets (approximately 400 houses). From the selected streets, all household members meeting the selection criteria were invited to participate in the study. One thousand subjects who met the criteria were approached and 642 participated in the study. In addition, community authorities requested that willing participants outside the random selection area should benefit from the study. Therefore volunteers (304 in 2008-2009 [cohort 1), and 308 in 2011 [cohort 2]) from the same community, but who were not part of the randomly selected streets or did not meet the age criteria, were also included.

\section{Recruitment strategy}

Information regarding the project was disseminated to residents through the local radio station, community newspaper, brochures and fliers; the latter bearing information about the project and distributed through school children and taxis by the recruitment team. Additionally, a 'road show' strategy that involved a celebrity suffering from diabetes from the same community was also used, especially in the targeted streets. Recruited subjects were visited by the recruitment team the evening before participation and reminded of all the survey instructions. These included overnight fasting, abstinence from drinking alcohol or consumption of any fluids in the morning of participation. Since the participants were required to bring in an early morning mid-stream urine sample, they were provided with a sterile container as well as instructions on how to collect the sample. Furthermore, participants were encouraged to bring along their medical/clinic cards and/or medication they were currently using.

\section{Identification of prediction models}

Existing prediction models were obtained from a systematic review by Brown et al. [9]. The search strategy from Brown's paper was re-run in PubMed for the timeperiod up to April 2014, to identify possible new models. The following string search was used, as per Brown et al:: (("type 2 diabetes" OR "hyperglycaemia" OR "hyperglycemia") AND ("risk scores))." Selected models were only those developed to predict the presence of undiagnosed diabetes. We focused on models developed using non-invasively measured predictors which were available in the Bellville-South cohort database. Models were excluded if they were developed for male and female individual separately.

\section{Outcome and predictors' definition and measurements}

The main outcome was newly diagnosed type 2 diabetes from the standard oral glucose tolerance test (OGTT), applying the World Health Organisation (WHO) criteria (i.e. fasting plasma glucose $\geq 7.0 \mathrm{mmol} / \mathrm{L}$ and/or $2 \mathrm{~h}$ plasma glucose $\geq 11.1 \mathrm{mmol} / \mathrm{L}$ ) [10]. At the baseline evaluation conducted between 2008 and 2011, participants received a face-to-face interview administered by trained personnel to collect data on personal and family history of diabetes mellitus, cardiovascular disease (CVD) and treatments; habits including smoking, alcohol consumption, physical activity and diet; demographics and education.

Clinical measurements included: height, weight, hip and waist circumferences and blood pressure (BP). BP measurements used a semi-automatic digital blood pressure monitor (Rossmax MJ90, USA) on the right arm, in sitting position, after a $10 \mathrm{~min}$ rest. The lowest value from three consecutive measurements 5 min apart was used in the current analysis. Weight to the nearest $0.1 \mathrm{~kg}$ was determined on a Sunbeam EB710 digital bathroom scale, with each subject in light clothing, 
without shoes and socks. Height to the nearest centimetre was measured with a stadiometer, with subjects standing on a flat surface. Body Mass Index (BMI) was calculated as weight per square meter $\left(\mathrm{kg} / \mathrm{m}^{2}\right)$.

Blood samples were collected and processed for a wide range of biochemical markers. Plasma glucose was measured by enzymatic hexokinase method (Cobas 6000, Roche Diagnostics, USA). High density lipoprotein cholesterol (HDL-c) and triglycerides (TG) were estimated by enzymatic colorimetric methods (Cobas 6000, Roche Diagnostics, USA).

\section{Assessment of model performance}

The original selected models were validated for the overall data and subsets using the formulas, without any recalibration. The predicted probability of undiagnosed diabetes for each participant was computed using the baseline measured predictors. The performance was expressed in terms of discrimination and calibration. Discrimination describes the ability of the model's performance in distinguishing those at a high risk of developing diabetes from those at low risk [11]. The discrimination was assessed and compared using concordance $(C)$ statistic and non-parametric methods [12].

Calibration describes the agreement between the probability of the outcome of interest as estimated by the model, and the observed outcome frequencies [13]. It was assessed graphically by plotting the predicted risk against the observed outcome rate. The agreement between the expected $(\mathrm{E})$ and observed $(\mathrm{O})$ rates $(\mathrm{E} / \mathrm{O})$ was assessed overall and within pre-specified groups of participants. The $95 \%$ confidence intervals for the expected/observed probabilities $(\mathrm{E} / \mathrm{O})$ ratio were calculated assuming a Poisson distribution [14]. We also calculated 1 ) the Yates slope, which is the difference between mean predicted probability of type 2 diabetes for participants with and without prevalent undiagnosed diabetes, with higher values indicate better performance; and 2) the Brier score, which is the squared difference between predicted probability and actual outcome for each participant with values ranging between 0 for a perfect prediction model and 1 for no match in prediction and outcome $[11,13]$. To determine optimal cut-off for maximising the potential effectiveness of a model, the Youden's J statistic (Youden's index) was used to determine the best threshold [15], with sensitivity, specificity and percentage of correctly classified individuals determined for each threshold. The main analysis was done for the overall cohort and for subgroups defined by sex, age ( $<60$ vs. $\geq 60$ years) and BMI $\left(<25 \mathrm{~kg} / \mathrm{m}^{2}\right.$ vs. $\left.\geq 25 \mathrm{~g} / \mathrm{m}^{2}\right)$.

\section{Sensitivity analysis}

To improve performance and eliminate differences in diabetes prevalence between the development population and the test population, models were recalibrated to the testpopulation-specific prevalence using intercept adjustment [16]. The correction factor calculated is based on the mean predicted risk and the prevalence in the validation set and is the natural logarithm of the odds ratio of the mean observed prevalence and the mean predicted risk [16]. To assess the potential effect on model performance of validation studies from complete case analysis, we also assess the discrimination of model across five datasets after application of multiple data imputation procedures to fill missing data.

\section{Results}

\section{Identification of prediction models}

Five non-invasive prevalent diabetes prediction models were selected for validation following the screening process; the Cambridge Risk Score [17], Kuwaiti Risk Score [18], Omani Diabetes Risk Score [19], Rotterdam Predictive Model 1 [20] and the simplified Finnish Diabetes Risk Score [21] (Fig. 1). Table 1 summarizes the models' characteristics. All models included age as a predictor, while a range of other predictors were variably combined in models. These included: sex, BMI, use of antihypertensive medication, family history of diabetes, waist circumference, past or current smoking and the use of corticosteroids. Additional 1: Table S1 comprises of the full equations for each of the models.

\section{Participants' characteristics}

A total of 1256 participants were examined in the Bellville South studies, including 173 with a history of diagnosed diabetes who were excluded. A further 346 participants were excluded for missing data on predictors or outcome variable. Therefore the final dataset comprised of 737 participants, of whom 580 (78.70\%) were female. In the Additional file 2: Table S2, we compare the profile of participants in the final sample vs. that of participants excluded for missing data. Excluded participants comprised more men ( 27.2 vs. $21.3 \%, p=0.012)$, were more likely to display a better lifestyle profile for alcohol intake (18.8\% vs. $28.1 \%, \mathrm{p}<0.001)$, smoking (31.8 \% vs. $43.8 \%, \mathrm{p}<0.001$ ), lower family history of diabetes (all $\mathrm{p} \leq 0.001)$, higher systolic blood pressure (126 vs. $123 \mathrm{mmHg}, \mathrm{p}=0.009$ ) and lower triglycerides (1.4 vs. $1.5 \mathrm{mmol} / \mathrm{l}, \mathrm{p}=0.043)$; although absolute differences were mostly clinically trivial.

The baseline profile for men and women included in the study is described in Table 2. The mean baseline age was 51.2 years overall, and 53.5 and 52.1 years, respectively in men and women $(\mathrm{p}=0.311)$. The BMI $(\mathrm{p}<0.001)$ waist circumference $(\mathrm{p}=0.024)$ and fasting blood glucose $(\mathrm{p}=$ $0.036)$ were significantly higher in women, while smoking $(\mathrm{p}<0.001)$ and alcohol consumption $(\mathrm{p}<0.001)$ were frequent among men. 


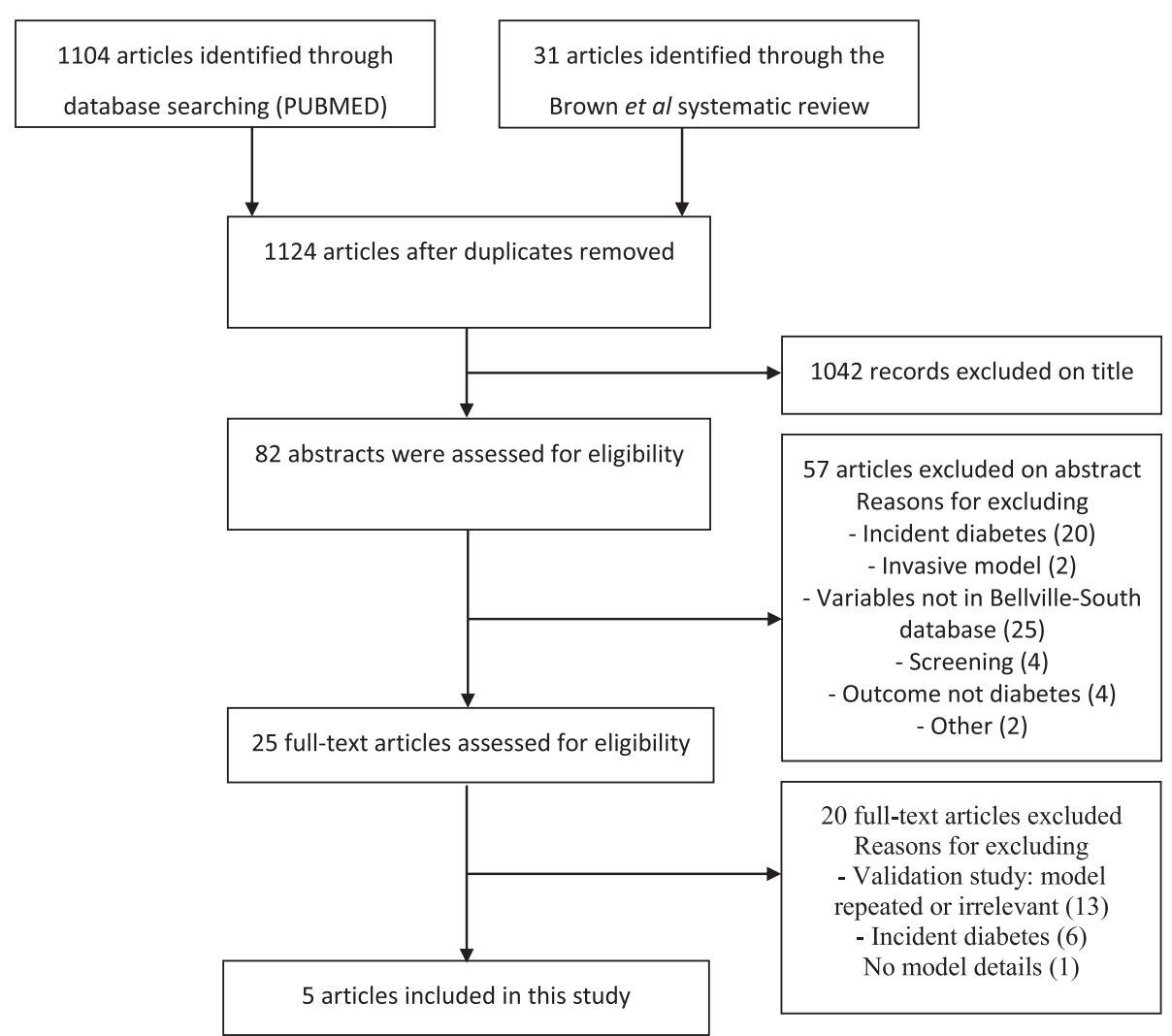

Fig. 1 Flow diagram of selected studies

\section{Prediction of prevalent undiagnosed diabetes in the overall sample}

A total of 130 participants (17.6\%) had prevalent undiagnosed diabetes. This prevalence was similar in men vs. women ( $14 \%$ vs. $18.6 \%, \mathrm{p}=0.220)$ (Table 2$)$. Table 1 and Additional file 1: Table S1 shows the discrimination for the selected prediction models in their original form in the overall sample. Discrimination was modest-toacceptable and similar between models, with C-statistics (95\% CI) ranging from 0.64 (0.59-0.69) for the Rotterdam model to $0.68(0.63-0.73)$ for the Kuwaiti model (all p > 0.05 for c-statistics comparison; Additional file 3: Table S3). At the total population level, the absolute risk of prevalent diabetes was acceptably estimated by the Omani model, overestimated by $81 \%$ (9-152\%) by the Cambridge model, underestimated by $74 \%$ (61-87 \%) by the Finnish model and marginally underestimated by the Kuwaiti and Rotterdam models (Table 1). The calibration curves are shown in Fig. 2 and supplemental Fig. 2. There was a systematic risk underestimation across the continuum of predicted probability by the Finnish and Rotterdam models, a selective upper strata risk overestimation by the Cambridge and Omani models, and a combination of both lower strata risk underestimation and upper strata risk overestimation by the Kuwaiti model.
Comparison of the C-statistics from the development study and the models' performance in this population shows a drop in performance of all the models. Other performance measures are shown in Table 1.

\section{Prediction of prevalent undiagnosed diabetes in subgroups}

The performance of the original models across subgroups was parallel to that in the overall dataset (Table 3). When comparing patterns of predictions across complementary subgroups, only stand-alone differences were seen in performance for a subgroup, which was not carried through all performance measures. Estimates of C-statistics were broadly similar across complementary subgroups, except for the Omani and Finnish models across BMI subgroups, whereby lower estimates were always found in the overweight/ obese subgroup. The pattern of the overall calibration (E/O) across complementary subgroups varied substantially across models. For instance, across gender subgroups, the overall diabetes risk was acceptably and equally predicted by the Omani model, equally underestimated by the Kuwaiti and Finnish models, equally overestimated by the Cambridge model, but acceptably estimated in men and underestimated in women by the 
Table 1 Overview of the included prevalent diabetes risk prediction models and their performance for the original model and the intercept adjusted model

\begin{tabular}{|c|c|c|c|c|c|c|c|c|c|c|c|}
\hline \multirow[b]{2}{*}{ Description } & \multicolumn{11}{|c|}{ Incident diabetes risk models } \\
\hline & \multicolumn{2}{|c|}{ Cambridge risk score } & \multicolumn{2}{|c|}{ Kuwaiti risk score } & \multicolumn{2}{|c|}{ Omani risk score } & \multicolumn{2}{|c|}{ Rotterdam predictive model 1} & \multicolumn{2}{|c|}{ Simplified Finnish risk score } & Bellville South \\
\hline Authors & \multicolumn{2}{|c|}{ Griffin et al. [17] } & \multicolumn{2}{|c|}{ Al Khalaf et al. [18] } & \multicolumn{2}{|c|}{ Al-Lawati \& Tuomilehto [19] } & \multicolumn{2}{|c|}{ Baan et al. [20] } & \multicolumn{2}{|c|}{ Bergmann et al. [21] } & - \\
\hline Year published & \multicolumn{2}{|l|}{2000} & \multicolumn{2}{|l|}{2008} & \multicolumn{2}{|l|}{2007} & \multicolumn{2}{|l|}{1999} & \multicolumn{2}{|l|}{2007} & - \\
\hline Country & \multicolumn{2}{|l|}{ UK } & \multicolumn{2}{|l|}{ Kuwaiti } & \multicolumn{2}{|l|}{ Oman } & \multicolumn{2}{|l|}{ Netherlands } & \multicolumn{2}{|l|}{ Germany } & South Africa \\
\hline Validation & \multicolumn{2}{|c|}{ External $[23-28,35]$} & \multicolumn{2}{|l|}{ None } & \multicolumn{2}{|l|}{ External [28] } & \multicolumn{2}{|c|}{ External $[23,27,29]$} & \multicolumn{2}{|c|}{ External $[23,27,28]$} & - \\
\hline Sample size & \multicolumn{2}{|l|}{1077} & 460 & & 4881 & & 1016 & & 526 & & 737 \\
\hline Type of study & Cross-sectional & & Cross-sectional & & Cross-sectional & & Cohort & & Cohort & & Cohort \\
\hline Age range & $40-79$ & & $20->40(36.2)$ & & $20-80$ & & $55-75$ & & $41-79$ & & $15-95$ \\
\hline Population & Caucasian & & Arab & & Arab & & Caucasian & & Caucasian & & Mixed ancestry \\
\hline Diagnosis of diabetes & $\begin{array}{l}\text { FBG } \geq 7.0 \mathrm{mmc} \\
\text { glucose } \geq 11.1\end{array}$ & $\begin{array}{l}\mathrm{ol} / / ; 2 \mathrm{~h} \\
\mathrm{mmol} / / \mathrm{l}\end{array}$ & $\begin{array}{l}\text { FBG } \geq 7.0 \mathrm{mmol} \\
\text { glucose } \geq 11.1 \mathrm{r}\end{array}$ & $\begin{array}{l}\text { l//; Random } \\
\mathrm{nmol} / /\end{array}$ & $\begin{array}{l}\text { FBG } \geq 7.0 \mathrm{~mm} \\
\text { glucose } \geq 11.1\end{array}$ & $\begin{array}{l}\mathrm{ol} / / ; 2 \mathrm{~h} \\
\mathrm{mmol} / \mathrm{l}\end{array}$ & $\begin{array}{l}\text { FBG } \geq 7.0 \mathrm{mmc} \\
\text { glucose } \geq 11.1\end{array}$ & $\begin{array}{l}\mathrm{ol} / \mathrm{l} ; 2 \mathrm{~h} \\
\mathrm{mmol} / / \mathrm{l}\end{array}$ & $\begin{array}{l}\text { FBG } \geq 7.0 \mathrm{mmol} \\
\text { glucose } \geq 11.1 \mathrm{n}\end{array}$ & $\begin{array}{l}\mathrm{l} / / / 2 \mathrm{~h} \\
\mathrm{mmol} / / \mathrm{l}\end{array}$ & $\begin{array}{l}\mathrm{FBG} \geq 7.0 \mathrm{mmol} / / ; 2 \mathrm{~h} \\
\text { glucose } \geq 11.1 \mathrm{mmol} / \mathrm{l}\end{array}$ \\
\hline $\begin{array}{l}\text { Development C- } \\
\text { statistic }\end{array}$ & $0.80(0.68-0.9$ & & 0.82 (NS) & & $0.83(0.82-0.8$ & & $0.68(0.64-0.7$ & & $0.75(0.68-0.8$ & & - \\
\hline Predictors & & & & & & & & & & & \\
\hline Age & Yes & & Yes & & Yes & & Yes & & Yes & & Yes \\
\hline Sex- & Yes & & No & & No & & Yes & & Yes & & Yes \\
\hline$B M I$ & Yes & & No & & Yes & & Yes & & Yes & & Yes \\
\hline Use of HTN drugs & Yes & & Yes & & No & & Yes & & Yes & & Yes \\
\hline Family history & Yes & & Yes & & Yes & & No & & Yes & & Yes \\
\hline WC & No & & Yes & & Yes & & No & & No & & Yes \\
\hline Smoking & Yes & & No & & No & & No & & Yes & & Yes \\
\hline Corticosteroids & Yes & & No & & No & & No & & Yes & & Yes \\
\hline Systolic/diastolic & No & & No & & Yes & & No & & No & & Yes \\
\hline Performance & Original & Adjusted & Original & Adjusted & Original & Adjusted & Original & Adjusted & Original & Adjusted & \\
\hline E/O (95 \% Cl) & $1.81(1.09-2.52)$ & $1.22(0.61-1.83)$ & $0.72(0.40-1.12)$ & $0.94(0.47-1.41)$ & $1.28(0.63-1.93)$ & $1.06(0.47-1.66)$ & $0.54(0.50-1.04)$ & $0.98(0.91-1.05)$ & $0.26(0.13-0.39)$ & $0.89(0.51-1.26)$ & - \\
\hline Brier score & 0.193 & 0.160 & 0.141 & 0.143 & 0.164 & 0.157 & 0.147 & 0.140 & 0.157 & 0.143 & - \\
\hline Yates slope & 0.379 & 0.379 & 0.496 & 0.496 & 0.392 & 0.392 & 0.971 & 0.971 & 0.491 & 0.491 & - \\
\hline C-statistic (95 \% Cl) & $0.67(0.62-0.72)$ & - & $0.68(0.63-0.73)$ & - & $0.66(0.61-0.70)$ & - & $0.64(0.59-0.69)$ & - & $0.67(0.62-0.71)$ & - & - \\
\hline Optimal threshold & 0.29 & 0.16 & 0.13 & 0.18 & 0.12 & 0.09 & 0.20 & 0.18 & 0.02 & 0.08 & - \\
\hline Sensitivity & 65 & 65 & 61 & 61 & 85 & 85 & 57 & 57 & 75 & 75 & - \\
\hline Specificity & 61 & 61 & 63 & 63 & 42 & 42 & 65 & 65 & 48 & 48 & - \\
\hline Correctly classified & 62 & 62 & 63 & 63 & 50 & 50 & 64 & 64 & 53 & 53 & - \\
\hline
\end{tabular}


Table 2 Characteristics comparison of participants with valid data between male and female

\begin{tabular}{|c|c|c|c|c|}
\hline & Male (157) & Female (580) & $p$-value & Overall (737) \\
\hline Prevalent undiagnosed DM (\%) & $22(14.0)$ & 108 (18.6) & 0.220 & $130(17.3)$ \\
\hline Age (years) & $53.5(15.0)$ & $52.1(14.3)$ & 0.311 & $52.2(14.5)$ \\
\hline Body mass index $\left(\mathrm{kg} / \mathrm{m}^{2}\right)$ & $25.5(5.8)$ & $29.6(7.0)$ & $<0.001$ & $29.4(7.1)$ \\
\hline Waist circumference (cm) & $92.5(15.2)$ & $95.6(14.7)$ & 0.024 & $95.9(14.9)$ \\
\hline Hypertensive medication (\%) & $43(27.4)$ & $208(35.9)$ & 0.059 & $251(34.1)$ \\
\hline Smoking status (\% smoking) & $88(56.1)$ & $235(40.5)$ & $<0.001$ & $323(43.8)$ \\
\hline Systolic blood pressure (mmHg) & $124.3(16.6)$ & $121.6(19.2)$ & 0.077 & $122.0(18.7)$ \\
\hline Diastolic blood pressure $(\mathrm{mmHg})$ & $75.6(11.1)$ & $74.7(12.1)$ & 0.365 & $74.7(11.9)$ \\
\hline Height (m) & $1.7(0.1)$ & $1.6(0.1)$ & $<0.001$ & $1.6(0.1)$ \\
\hline Mother having diabetes (\%) & $17(10.8)$ & $92(15.9)$ & 0.147 & 109 (14.8) \\
\hline Father having diabetes (\%) & $14(8.9)$ & $44(7.6)$ & 0.702 & $58(7.9)$ \\
\hline Sister having diabetes (\%) & $12(7.6)$ & $80(13.8)$ & 0.053 & $92(12.5)$ \\
\hline Brother having diabetes (\%) & $9(5.7)$ & $49(8.5)$ & 0.340 & $58(7.9)$ \\
\hline Fasting blood glucose (mmol/L) & $5.4(1.4)$ & $5.7(2.0)$ & 0.036 & $5.8(1.9)$ \\
\hline $\mathrm{HDL}(\mathrm{mmol} / \mathrm{L})$ & $1.2(0.4)$ & $1.3(0.3)$ & 0.136 & $1.3(0.3)$ \\
\hline Weight (kg) & $72.3(16.4)$ & $73.9(17.7)$ & 0.290 & $74.1(17.5)$ \\
\hline Ever consumed alcohol (\%) & $116(73.9)$ & $240(41.4)$ & $<0.001$ & $356(48.3)$ \\
\hline Current drinking (\%) & $80(51.0)$ & $127(21.9)$ & $<0.001$ & $207(28.1)$ \\
\hline Using Corticosteroid use (\%) & $1(0.6)$ & $4(0.7)$ & $>0.99$ & $5(0.7)$ \\
\hline Triglyceride (mmol/L) & $1.4(0.9)$ & $1.4(0.9)$ & 0.836 & $1.4(0.9)$ \\
\hline
\end{tabular}

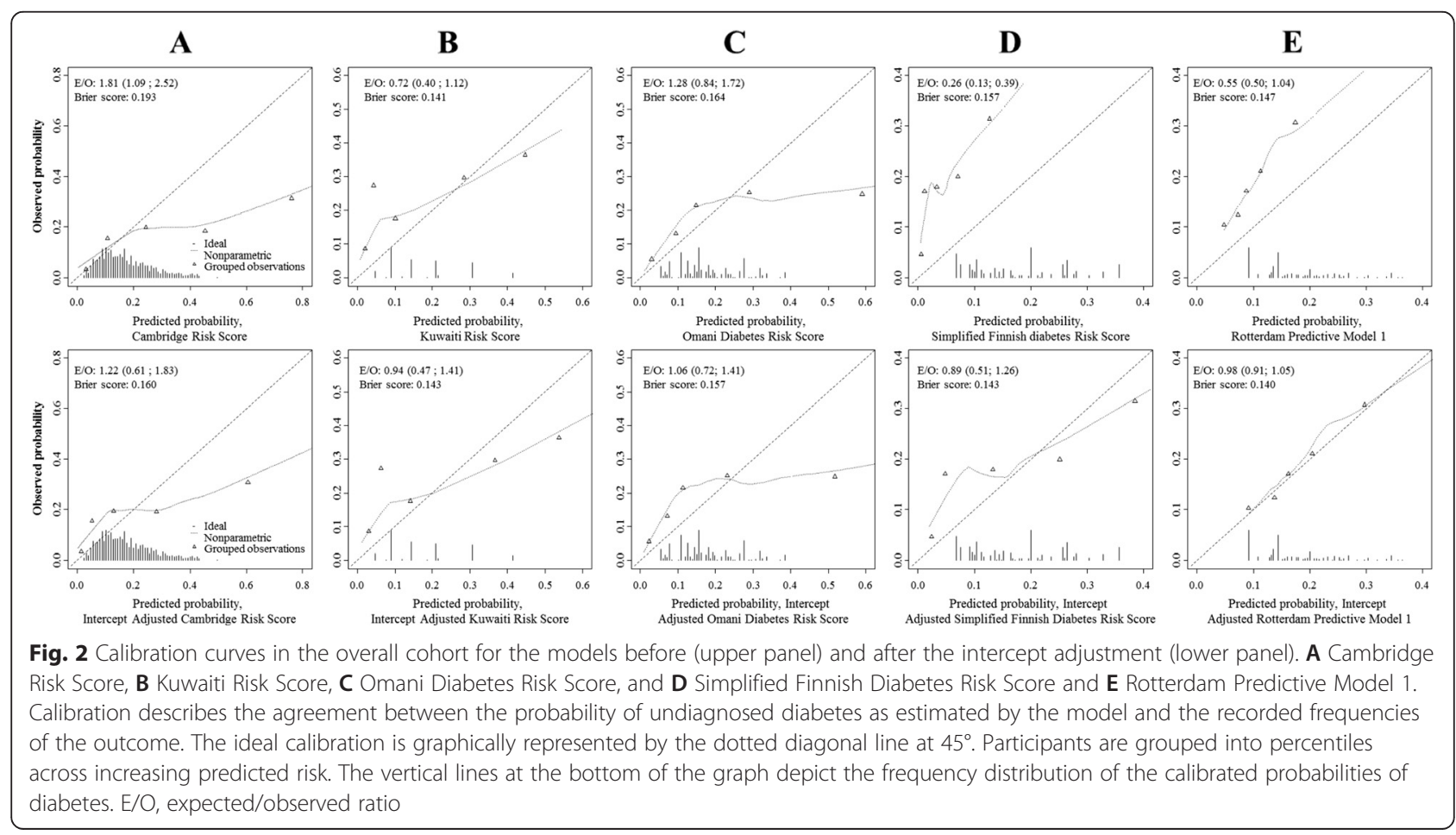


Table 3 Discrimination and calibration statistics for diabetes risk model performance in subgroups of participants by gender, age and body mass index (BMI)

\begin{tabular}{|c|c|c|c|c|c|c|c|}
\hline Models & & Male & Female & Age $<60$ years & Age $\geq 60$ years & $\mathrm{BMl}<25 \mathrm{~kg} / \mathrm{m}^{2}$ & $\mathrm{BMI} \geq 25 \mathrm{~kg} / \mathrm{m}^{2}$ \\
\hline \multirow[t]{4}{*}{ Cambridge Diabetes Risk Score [17] } & $\mathrm{E} / \mathrm{O}(95 \% \mathrm{Cl})$ & $2.30(1.21-3.37)$ & $1.71(1.00-1.41)$ & $1.57(0.71-2.44)$ & $2.10(1.51-2.69)$ & $1.08(0.55-1.61)$ & $1.96(1.30-2.63)$ \\
\hline & Brier score & 0.195 & 0.192 & 0.151 & 0.282 & 0.102 & 0.230 \\
\hline & Yates slope & 0.373 & 0.384 & 0.368 & 0.384 & 0.450 & 0.368 \\
\hline & C-statistic $(95 \% \mathrm{Cl})$ & $0.67(0.56-0.78)$ & $0.67(0.62-0.73)$ & $0.66(0.60-0.72)$ & $0.65(0.56-0.73)$ & $0.69(0.58-0.79)$ & $0.64(0.59-0.70)$ \\
\hline \multirow[t]{4}{*}{ Kuwaiti Risk Score [18] } & E/O (95 \% Cl) & $0.73(0.40-1.06)$ & $0.72(0.34-1.10)$ & $0.73(0.37-1.10)$ & $0.71(0.32-1.11)$ & $0.33(0.20-0.46)$ & $0.81(0.43-1.19)$ \\
\hline & Brier score & 0.112 & 0.149 & 0.121 & 0.186 & 0.097 & 0.159 \\
\hline & Yates slope & 0.588 & 0.468 & 0.476 & 0.449 & 0.890 & 0.468 \\
\hline & C-statistic $(95 \% \mathrm{Cl})$ & $0.70(0.58-0.82)$ & $0.67(0.61-0.72)$ & $0.67(0.61-0.74)$ & $0.65(0.57-0.73)$ & $0.61(0.51-0.72)$ & $0.66(0.60-0.71)$ \\
\hline \multirow[t]{4}{*}{ Omani Diabetes Risk Score [19] } & E/O (95 \% Cl) & $1.33(0.45-2.20)$ & $1.32(0.65-2.00)$ & $1.26(0.53-1.99)$ & $1.40(0.60-2.20)$ & $1.16(0.41-1.92)$ & $1.36(0.71-2.01)$ \\
\hline & Brier score & 0.137 & 0.173 & 0.140 & 0.221 & 0.096 & 0.194 \\
\hline & Yates slope & 0.347 & 0.399 & 0.393 & 0.296 & 0.620 & 0.304 \\
\hline & C-statistic (95\% Cl) & $0.62(0.49-0.74)$ & $0.66(0.61-0.71)$ & $0.66(0.60-0.71)$ & $0.60(0.52-0.68)$ & $0.71(0.61-0.82)$ & $0.61(0.56-0.67)$ \\
\hline \multirow[t]{4}{*}{ Rotterdam Predictive Model 1 [20] } & E/O (95 \% Cl) & $0.84(-0.38-2.06)$ & $0.48(0.45-0.93)$ & $0.52(0.44-0.96)$ & $0.49(0.39-0.88)$ & $0.72(0.34-1.06)$ & $0.51(0.45-0.96)$ \\
\hline & Brier score & 0.117 & 0.155 & 0.125 & 0.199 & 0.096 & 0.168 \\
\hline & Yates slope & 0.913 & 1.154 & 1.135 & 0.838 & 0.791 & 0.886 \\
\hline & C-statistic $(95 \% \mathrm{Cl})$ & $0.62(0.49-0.75)$ & $0.66(0.60-0.72)$ & $0.62(0.55-0.69)$ & $0.61(0.52-0.69)$ & $0.61(0.50-0.72)$ & $0.63(0.57-0.69)$ \\
\hline \multirow[t]{4}{*}{ Simplified Finnish Diabetes Risk score [21] } & E/O (95 \% Cl) & $0.22(0.09-0.35)$ & $0.32(0.18-0.45)$ & $0.34(0.18-0.50)$ & $0.26(0.14-0.37)$ & $0.11(0.06-0.15)$ & $0.34(0.21-0.48)$ \\
\hline & Brier score & 0.128 & 0.162 & 0.128 & 0.213 & 0.103 & 0.176 \\
\hline & Yates slope & 0.538 & 0.591 & 0.487 & 0.608 & 1.345 & 0.562 \\
\hline & C-statistic (95\% Cl) & $0.70(0.59-0.81)$ & $0.66(0.60-0.71)$ & $0.64(0.58-0.71)$ & $0.67(0.60-0.75)$ & $0.77(0.69-0.86)$ & $0.62(0.57-0.68)$ \\
\hline
\end{tabular}


Rotterdam model (Table 3). Other performance measures across subgroups are shown in Table 3.

\section{Performance of the intercept adjusted models}

As expected, intercept adjustment yielded acceptable agreement between predicted and observed prevalent diabetes rates at the total population level. A perfect agreement was also observed across the continuum of the predicted probability by the updated Rotterdam model. However, despite some attenuation, selective upper strata risk overestimations were apparent for other models.

\section{Model performance at the optimal threshold}

The performances of models at the optimal thresholds are shown in Table 1. As expected, the optimal threshold probability for our sample varied across models and for the same model between the original and intercept adjusted versions. The sensitivity at the optimal threshold ranged from $61 \%$ for the Kuwaiti model to $85 \%$ with the Omani model, the specificity from $42 \%$ (Omani model) to $65 \%$ (Rotterdam model), and the proportion of participants correctly classified from 50 \% (Omani model) to $64 \%$ (Rotterdam model).

\section{Model performance after multiple imputation of missing data}

The discrimination (c-statistic) of models across five datasets obtained after multiple imputation of missing data was very similar: $0.69(0.64-0.73)$ for the Cambridge model, $0.69(0.65-0.74)$ for the Kuwaiti model, $0.65(0.61-0.69)$ for the Omani model, $0.65(0.60-0.69)$ for the Rotterdam model and $0.66(0.62-0.70)$ for the Finnish model. The values were also very similar to those from the validation of models on dataset comprising only participants with complete data (Table 1).

\section{Discussion}

To our knowledge, this is the largest and most comprehensive validation study of prevalent diabetes prediction models in a sub-Saharan African population. In the Bellville South cohort, the selected existing prediction models based upon non-invasive measured predictors had modest-to-acceptable discriminatory ability to predict prevalent undiagnosed diabetes, both overall and within subgroups. Simple intercept adjustment had mixed effect on the calibration performance of the models, while none of the models was significantly better than other models to be uniquely recommended for use in this setting. At the optimal probability thresholds, the best performing model would correctly classify only about $2 / 3^{\text {rd }}$ of the population, indicating the existing scope for further improving the models' performance in this setting.
The need for diabetes screening programs is imperative in the reduction of the worldwide burden of complications from diabetes in undiagnosed individuals. In view of the large and continuously growing burden of diabetes the Centre for Disease Control strongly advocates for diabetes screening programs. In its most recent guidelines for type 2 diabetes screening and diagnosis, the International Diabetes Federation has recommended that each health service should decide on programs to detect undiagnosed diabetes based on the prevalence and the resources available in that region [3]. In areas with limited care, such as developing countries, the detection programs are suggested to be opportunistic and should be limited to high-risk individuals. The World Health Organization African region promotes the screening of at-risk individuals in Africa in healthcare settings and social gatherings [22]. Risk assessment scores are feasible and cost-effective and can be considered, but applicability must be certain, with the required tests available in the area and the validation of that risk score in the population.

With the exception of the Kuwaiti model [18], all other models assessed in our study have been validated externally. The most validated appeared to be the Cambridge model [17], with c-statistics ranging from 0.67 to 0.83 across validation studies [23-27]. With a cstatistic of 0.67 in the Bellville South data set, the Cambridge model performance in this population fell to the bottom end of other validation study results. Similarly, the Finnish model's discrimination performance (c-statistic: 0.67) also compared with lower c-statistic's from validation studies [23, 27, 28]. The Rotterdam model mirrored the validation study results (0.64 vs. $0.63-0.65)$ $[23,27,29]$, while the Omani model underperformed (c-statistic: 0.66 ) when compared to the only validation study the authors are aware of (c-statistic: 0.72) [28].

Through an attempt to improve calibration with simple intercept adjustment, the E/O ratios for all models were improved. Despite the expected decision that no model was ready for immediate implementation, the Rotterdam Predictive Model 1 showed the best improvement in calibration following this adjustment. A review by Brown et al. in 2012 [9] of 17 undiagnosed Type 2 diabetes risk scores, which included all five models discussed here, determined that performance was not associated to the number of predictors in the model. Overall, validation studies showed a drop in model performance when tested in a new population, with the Rotterdam model having the lowest validation performance range, when compared to the other models. This was echoed in our results for the original Rotterdam model validation. The possible reasons to explain the drop in the performance of diabetes prediction models in new population, some of which apply to our study, have been extensively discussed elsewhere [30]. 
At the optimal probability threshold, the models tested in our study would at best correctly detect two-thirds of participants, with diagnostic performance mostly similar to those from published studies $[25,30]$. This indicates the existing scope for improving the performance of diabetes prediction models in our setting. This could be done by adopting or developing models enriched with predictors to improve the predictive accuracy. Such an approach however, has to be balanced against the fact that the number of predictors and the complexity and cost of their measurements are severe limitations for their uptake in routine practice [30]. What is probably needed the most in resources limited settings like Africa is evidence to confirm that the introduction of diabetes prediction models in routine practice will improve early detection of diabetes by healthcare practitioners, and the outcome of those diagnosed with diabetes in the long run.

The results of this study were strengthened by the diagnosis of diabetes based on OGTT, thus limiting the risk of misclassification. The age distribution was wide, including a vast majority of the high-risk population. A potential limitation of the study was the exclusion of some risk scores due to the necessary information being unavailable. The fewer number of males in the final dataset could have played a role in the performance of the models, owing to the significant difference between the genders in BMI, a predictor in four out of the five models. No power estimation was done, in the absence of consensus methods for sample size estimation in model validation studies. However, studies have suggested that at least 100 events and 100 non-events were the minimum required samples for external validation studies [31]. These requirements were largely met in our main analysis. Our study participants comprised a subset of randomly selected individuals and subset of selfselected participants from the same community. In the absence of any influence on participants' selection of a prior knowledge of the association between relevant study outcomes and predictors included in tested model, any differential effect of the sample selection strategy on the discriminatory performance of tested models, is very unlikely. The prevalence of screen-detected diabetes in our randomly selected participants alones has been estimated to be $18.1 \%$ [32], which is very close to the $17.6 \%$ found in combined sample, suggested the absence of a differential effect on the calibration performance of models. The total number of participants with screendetected diabetes in the combined sample precluded reliable stratified analyses to investigate and confirm the assumptions above. Finally, a substantial number of participants were excluded from the main analyses due to missing data on predictors included in models or on the status for prevalent undiagnosed diabetes. However, participants with complete data were mostly similar to those with missing data, particularly regarding the distribution of key predictors included in models such as age, gender and measures of adiposity. Therefore, differential effect on the model performance of validation based on complete case analyses, is very unlikely. Indeed, in sensitivity analysis, the discriminatory performance of models was very similar across multiple imputed datasets, and not appreciable different from the performance based on complete case analysis. Furthermore, variables with high frequency of missingness were likely to be those that are very difficult to accurately measure in routine setting like family history of diabetes, and therefore, less indicated for uncritical inclusion in models for predicting diabetes across settings [33, 34].

\section{Conclusions}

Our findings highlight the performance variation of models differs across different populations, particularly calibration. This low performance can be explained by the obvious lack of transportability due to the differences in development and validation population characteristics and the affect case-mix difference has on model performance. With no model development in the mixed ancestry population of South Africa, selection of generalizable models for validation was limited. There is a great clinical need for a unique, robust and convenient tool for identifying undiagnosed diabetes and predicating future diabetes quicker and more economically in this South African population. Through efficient application of prediction models' improvement procedures, the final model would improve risk assessment specific to this community. With no acceptable validated model, unique model development is possibly the best way forward.

\section{Additional files}

Additional file 1: Table S1. Full equation for risk models to predict prevalent undiagnosed diabetes as applied to the Bellville South cohort. Additional file 2: Table S2. Characteristics comparison of participants with valid and missing data.

Additional file 3: Table S3. Discrimination values and $95 \%$ confidence intervals for selected models and the comparison of the discrimination between each model, expressed using p-value ( $<0.05$ significant).

\section{Competing interests}

The authors declare that they have no competing interests.

\section{Authors' contributions}

Study conception and data acquisition: TEM, RTE, APK. Data analysis and interpretation: KM, APK. Manuscript drafting: KM, APK. Manuscript revision: TEM, RTE. Approval of the submission: all co-authors. All authors read and approved the final manuscript. 


\section{Acknowledgements}

Katya Masconi was supported by a scholarship from the South African National Research Foundation and the Carl \& Emily Fuchs Foundation.

\section{Author details}

'Division of Chemical Pathology, Stellenbosch University, Cape Town, South Africa. ${ }^{2}$ Non-Communicable Diseases Research Unit, South African Medical Research Council, Cape Town, South Africa. ${ }^{3}$ Faculty of Health and Wellness Sciences, Cape Peninsula University of Technology, Cape Town, South Africa. ${ }^{4}$ Department of Medicine, Groote Schuur Hospital, University of Cape Town, Cape Town, South Africa.

Received: 27 January 2015 Accepted: 1 May 2015

Published online: 09 May 2015

\section{References}

1. Guariguata L, Whiting DR, Hambleton I, Beagley J, Linnenkamp U, Shaw JE. Global estimates of diabetes prevalence for 2013 and projections for 2035. Diabetes Res Clin Pract. 2014;103(2):137-49.

2. Alberti KG, Zimmet $P$, Shaw J. International Diabetes Federation: a consensus on Type 2 diabetes prevention. Diabet Med. 2007;24(5):451-63.

3. Clinical Guidelines Task Force: Global guidelines for type 2 diabetes. Geneva; 2012

4. Collins GS, Mallett S, Omar O, Yu LM. Developing risk prediction models for type 2 diabetes: a systematic review of methodology and reporting. BMC Med. 2011;9:103.

5. Buijsse B, Simmons RK, Griffin SJ, Schulze MB. Risk assessment tools for identifying individuals at risk of developing type 2 diabetes. Epidemiol Rev. 2011;33(1):46-62.

6. Moons KG, Kengne AP, Grobbee DE, Royston P, Vergouwe Y, Altman DG, et al. Risk prediction models: II. External validation, model updating, and impact assessment. Heart. 2012;98(9):691-8.

7. Moons KG, Kengne AP, Woodward M, Royston P, Vergouwe Y, Altman DG, et al. Risk prediction models: I. Development, internal validation, and assessing the incremental value of a new (bio) marker. Heart. 2012;98(9):683-90.

8. Matsha TE, Hassan MS, Kidd M, Erasmus RT. The 30-year cardiovascular risk profile of South Africans with diagnosed diabetes, undiagnosed diabetes, pre-diabetes or normoglycaemia: the Bellville, South Africa pilot study. Cardiovasc J Africa. 2012;23(1):5-11.

9. Brown N, Critchley J, Bogowicz P, Mayige M, Unwin N. Risk scores based on self-reported or available clinical data to detect undiagnosed type 2 diabetes: a systematic review. Diabetes Res Clin Pract. 2012;98(3):369-85.

10. Alberti KG, Zimmet P. Definition, diagnosis and classification of diabetes mellitus and its complications. Part 1: diagnosis and classification of diabetes mellitus provisional report of a WHO consultation. Diabet Med. 1998;15:539-53.

11. Kengne AP, Masconi K, Mbanya VN, Lekoubou A, Echouffo-Tcheugui JB, Matsha TE. Risk predictive modelling for diabetes and cardiovascular disease. Crit Rev Clin Lab Sci. 2014;51(1):1-12.

12. DeLong ER, DeLong DM, Clarke-Pearson DL. Comparing the areas under two or more correlated receiver operating characteristic curves: a nonparametric approach. Biometrics. 1988;44(3):837-45.

13. Steyerberg EW, Vickers AJ, Cook NR, Gerds T, Gonen M, Obuchowski N, et al. Assessing the performance of prediction models: a framework for traditional and novel measures. Epidemiology. 2010;21 (1):128-38.

14. Dobson AJ, Kuulasmaa K, Eberle E, Scherer J. Confidence intervals for weighted sums of Poisson parameters. Stat Med. 1991;10(3):457-62.

15. Youden WJ. Index for rating diagnostic tests. Cancer. 1950;3(1):32-5.

16. Janssen KJ, Moons KG, Kalkman CJ, Grobbee DE, Vergouwe Y. Updating methods improved the performance of a clinical prediction model in new patients. J Clin Epidemiol. 2008;61(1):76-86.

17. Griffin SJ, Little PS, Hales CN, Kinmonth AL, Wareham NJ. Diabetes risk score: towards earlier detection of type 2 diabetes in general practice. Diabetes Metab Res Rev. 2000;16(3):164-71.

18. Al Khalaf MM, Eid MM, Najjar HA, Alhajry KM, Doi SA, Thalib L. Screening for diabetes in Kuwait and evaluation of risk scores. East Mediterr Health J. 2010;16(7):725-31.

19. Al-Lawati JA, Tuomilehto J. Diabetes risk score in Oman: a tool to identify prevalent type 2 diabetes among Arabs of the Middle East. Diabetes Res Clin Pract. 2007;77(3):438-44.
20. Baan CA, Ruige JB, Stolk RP, Witteman JC, Dekker JM, Heine RJ, et al. Performance of a predictive model to identify undiagnosed diabetes in a health care setting. Diabetes Care. 1999;22(2):213-9.

21. Bergmann A, Li J, Wang L, Schulze J, Bornstein SR, Schwarz PE. A simplified Finnish diabetes risk score to predict type 2 diabetes risk and disease evolution in a German population. Horm Metab Res. 2007;39(9):677-82.

22. Sambo BH. The diabetes strategy for the WHO African Region: a call to action. Diabetes Voice. 2007;52(4):335-7.

23. Gao WG, Dong YH, Pang ZC, Nan HR, Wang SJ, Ren J, et al. A simple Chinese risk score for undiagnosed diabetes. Diabet Med. 2010;27(3):274-81.

24. Spijkerman AM, Yuyun MF, Griffin SJ, Dekker JM, Nijpels G, Wareham NJ. The performance of a risk score as a screening test for undiagnosed hyperglycemia in ethnic minority groups: data from the 1999 health survey for England. Diabetes Care. 2004;27(1):116-22.

25. Park PJ, Griffin SJ, Sargeant L, Wareham NJ. The performance of a risk score in predicting undiagnosed hyperglycemia. Diabetes Care. 2002;25(6):984-8.

26. Heldgaard PE, Griffin SJ. Routinely collected general practice data aids identification of people with hyperglycaemia and metabolic syndrome. Diabet Med. 2006;23(9):996-1002.

27. Witte DR, Shipley MJ, Marmot MG, Brunner EJ. Performance of existing risk scores in screening for undiagnosed diabetes: an external validation study. Diabet Med. 2010;27(1):46-53.

28. Lin JW, Chang YC, Li HY, Chien YF, Wu MY, Tsai RY, et al. Cross-sectional validation of diabetes risk scores for predicting diabetes, metabolic syndrome, and chronic kidney disease in Taiwanese. Diabetes Care. 2009;32(12):2294-6.

29. Lee YH, Bang H, Kim HC, Kim HM, Park SW, Kim DJ. A simple screening score for diabetes for the Korean population: development, validation, and comparison with other scores. Diabetes Care. 2012;35(8):1723-30.

30. Kengne AP, Beulens JW, Peelen LM, Moons KG, van der Schouw YT, Schulze MB, et al. Non-invasive risk scores for prediction of type 2 diabetes (EPIC-InterAct): a validation of existing models. Lancet Diabetes Endocrinol. 2014;2(1):19-29.

31. Vergouwe Y, Steyerberg EW, Eijkemans MJ, Habbema JD. Substantial effective sample sizes were required for external validation studies of predictive logistic regression models. J Clin Epidemiol. 2005;58(5):475-83.

32. Erasmus RT, Soita DJ, Hassan MS, Blanco-Blanco E, Vergotine Z, Kengne AP, et al. High prevalence of diabetes mellitus and metabolic syndrome in a South African coloured population: baseline data of a study in Bellville, Cape Town. S Afr Med J. 2012;102(11 Pt 1):841-4.

33. Wilson BJ, Qureshi N, Santaguida P, Little J, Carroll JC, Allanson J, et al. Systematic review: family history in risk assessment for common diseases. Annals Internal Med. 2009;151(12):878-85.

34. Qureshi N, Wilson B, Santaguida P, Little J, Carroll J, Allanson J, et al. Family history and improving health. 2009.

35. Rahman M, Simmons RK, Harding AH, Wareham NJ, Griffin SJ. A simple risk score identifies individuals at high risk of developing Type 2 diabetes: a prospective cohort study. Fam Pract. 2008;25(3):191-6.

\section{Submit your next manuscript to BioMed Central and take full advantage of:}

- Convenient online submission

- Thorough peer review

- No space constraints or color figure charges

- Immediate publication on acceptance

- Inclusion in PubMed, CAS, Scopus and Google Scholar

- Research which is freely available for redistribution 